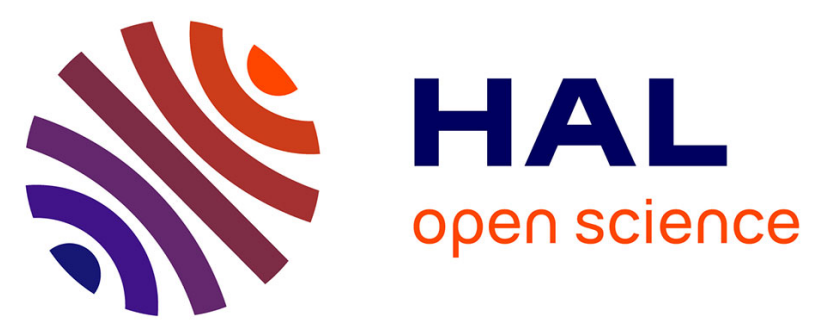

\title{
Examining the interaction between multi-year landfast sea ice and the Mertz Glacier Tongue, East Antarctica: Another factor in ice sheet stability?
}

Robert A. Massom, A. Barry Giles, Helen A. Fricker, Benoit Legresy, Roland C. Warner, Glenn Hyland, Neal Young, Alexander D. Fraser

\section{To cite this version:}

Robert A. Massom, A. Barry Giles, Helen A. Fricker, Benoit Legresy, Roland C. Warner, et al.. Examining the interaction between multi-year landfast sea ice and the Mertz Glacier Tongue, East Antarctica: Another factor in ice sheet stability?. Journal of Geophysical Research. Oceans, 2010, 115 (C12027), pp.C12027. 10.1029/2009JC006083 . hal-00561641

\section{HAL Id: hal-00561641 \\ https://hal.science/hal-00561641}

Submitted on 3 Jan 2022

HAL is a multi-disciplinary open access archive for the deposit and dissemination of scientific research documents, whether they are published or not. The documents may come from teaching and research institutions in France or abroad, or from public or private research centers.
L'archive ouverte pluridisciplinaire HAL, est destinée au dépôt et à la diffusion de documents scientifiques de niveau recherche, publiés ou non, émanant des établissements d'enseignement et de recherche français ou étrangers, des laboratoires publics ou privés.

$$
\text { Copyright }
$$




\title{
Examining the interaction between multi-year landfast sea ice and the Mertz Glacier Tongue, East Antarctica: Another factor in ice sheet stability?
}

\author{
Robert A. Massom, ${ }^{1,2}$ A. Barry Giles, ${ }^{2}$ Helen A. Fricker, ${ }^{3}$ Roland C. Warner, ${ }^{1,2}$ \\ Benoit Legrésy, ${ }^{4}$ Glenn Hyland, ${ }^{1,2}$ Neal Young, ${ }^{1,2}$ and Alexander D. Fraser ${ }^{2,5}$ \\ Received 23 December 2009; revised 29 July 2010; accepted 13 September 2010; published 14 December 2010.
}

[1] The Mertz Glacier tongue (MGT), East Antarctica, has a large area of multi-year fast sea ice (MYFI) attached to its eastern edge. We use various satellite data sets to study the extent, age, and thickness of the MYFI and how it interacts with the MGT. We estimate its age to be at least 25 years and its thickness to be $10-55 \mathrm{~m}$; this is an order of magnitude thicker than the average regional sea-ice thickness and too thick to be formed through sea-ice growth alone. We speculate that the most plausible process for its growth after initial formation is marine (frazil) ice accretion. The satellite data provide two types of evidence for strong mechanical coupling between the two types of ice: The MYFI moves with the MGT, and persistent rifts that originate in the MGT continue to propagate for large distances into the MYFI. The area of MYFI decreased by $50 \%$ following the departure of two large tabular icebergs that acted as pinning points and protective barriers. Future MYFI extent will be affected by subsequent icebergs from the Ninnis Glacier and the imminent calving of the MGT. Fast ice is vulnerable to changing atmospheric and oceanic conditions, and its disappearance may have an influence on ice tongue/ice shelf stability. Understanding the influence of thick MYFI on floating ice tongues/ice shelves may be significant to understanding the processes that control their evolution and how these respond to climate change, and thus to predicting the future of the Antarctic Ice Sheet.

Citation: $\quad$ Massom, R. A., A. B. Giles, H. A. Fricker, R. C. Warner, B. Legrésy, G. Hyland, N. Young, and A. D. Fraser (2010), Examining the interaction between multi-year landfast sea ice and the Mertz Glacier Tongue, East Antarctica: Another factor in ice sheet stability?, J. Geophys. Res., 115, C12027, doi:10.1029/2009JC006083.

\section{Introduction}

[2] Accurate knowledge of the mass balance of the Antarctic Ice Sheet and its change is required to determine its response to climate change and its contribution to global sea level rise [Payne and Bamber, 2004]. Antarctic ice streams are critical for the mass balance of the ice sheet because they control its output, transporting mass from the ice-sheet interior to margins, typically to ice shelves or glacier tongues and ultimately to the ocean [Rignot et al., 2008]. Fast-flowing regions of the ice sheet such as ice streams and outlet glaciers are thought to be particularly susceptible to rapid change

\footnotetext{
${ }^{1}$ Australian Antarctic Division, Department of Sustainability, Environment, Water, Population and Communities, Kingston, Tasmania, Australia.

${ }^{2}$ Antarctic Climate and Ecosystems Cooperative Research Centre, University of Tasmania, Sandy Bay, Tasmania, Australia.

${ }^{3}$ Institute of Geophysics and Planetary Physics, Scripps Institution of Oceanography, University of California, San Diego, La Jolla, California, USA.

${ }^{4}$ LEGOS, CNRS, Toulouse, France.

${ }^{5}$ Institute of Marine and Antarctic Studies, University of Tasmania, Sandy Bay, Tasmania, Australia.

Copyright 2010 by the American Geophysical Union. 0148-0227/10/2009JC006083
}

under a global warming scenario [Alley and Whillans, 1991; Alley and Bindschadler, 2001]. Moreover, floating glacier tongues (and ice shelves) are considered vulnerable to rapid climate change through direct contact with the ocean [Joughin et al., 2008; Rignot and Jacobs, 2002; Williams et al., 2002; Shepherd et al., 2004] and as sensitive indicators of the effects of ocean warming. Recent observations of tributary glacier speed-ups following ice shelf retreat $[D e$ Angelis and Skvarca, 2003; Rignot et al., 2004; Scambos et al., 2004] have confirmed the "buttressing" role of ice shelves in restraining flow in outlet glaciers and ice streams [Hughes, 1977]. Similar observations in Greenland show that outlet glaciers respond to changes in the floating glacier tongues [Thomas, 2004; Joughin et al., 2004, 2008]. These observations all confirm that the grounded ice sheet is tightly coupled to the ice shelves/glacier tongues, which exert strong control on ice sheet mass loss at the grounding line and thus influence global sea level. Ice shelves and glacier tongues should therefore be adequately represented in coupled Earth system models that attempt to predict changes in the ice sheet mass balance. This points to an urgent need to understand how glacier tongues and ice shelves will evolve in a warming climate and to identify the processes that control their evolution and their sensitivity to climate forcing. 


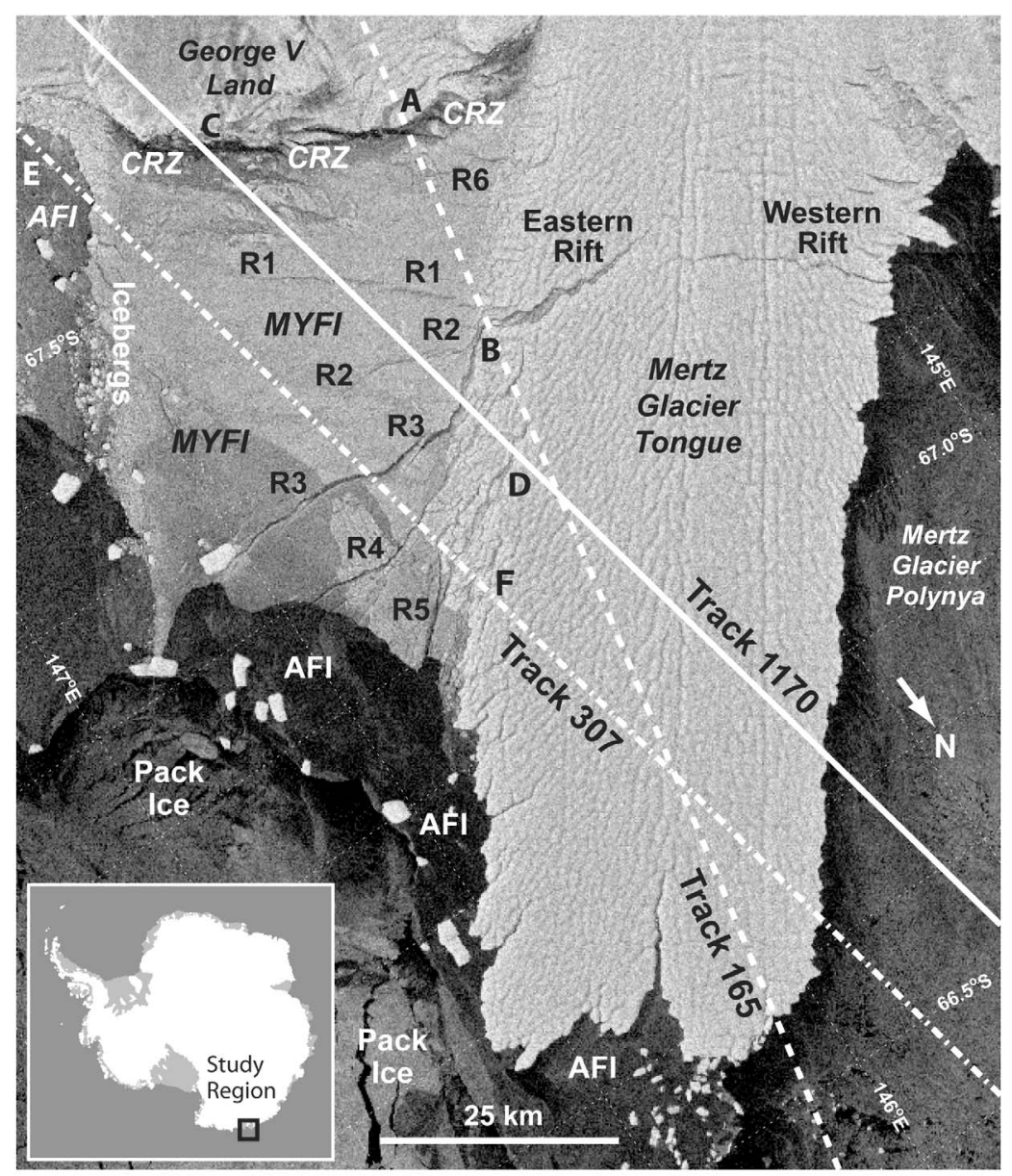

Figure 1. Radarsat ScanSAR image of MGT from 5 September 2003 showing ICESat tracks used in this study, with six lateral rifts through the fast ice marked [R1-R6]. AFI is annual fast ice. Other features marked correspond to those in Figure 6. SAR imagery CNASA/Canadian Space Agency.

[3] One component of the ice shelf-ocean system that has scarcely been considered is multi-year "fast ice," which fringes much of the Antarctic Ice Sheet in a narrow and discontinuous band. Fast ice is sea ice that forms and becomes fixed or "fast" to a shoreline, grounded icebergs, islands, or the ice fronts of a grounded ice sheet or floating ice shelves [World Meteorological Organization, 1970]. While most regions of fast ice are annual, forming each autumn and breaking out each spring and summer [e.g., Massom et al., 2009], areas of thicker fast ice persist year-round in certain locations, e.g., more sheltered embayments [Giles et al., 2008], including regions where the ocean is deeper than $\sim 400 \mathrm{~m}$ [Massom, 2003]. Grounded icebergs play a significant role in determining Antarctic fast ice distribution in waters shallower than this by forming "anchor points" for ice growth and the interception of pack ice [Giles et al., 2008; Massom et al., 2009].

[4] An important region of multi-year fast ice (MYFI) in East Antarctica occurs to the southeast of the floating Mertz Glacier tongue (MGT) (Figure 1). This MYFI is attached to the eastern edge of the MGT and extends south to the continental margin. In this sheltered location, the fast ice has been protected from encroaching pack ice drifting westward with the Antarctic Coastal Current by the presence of large grounded iceberg B-9B (until recently centered on $\sim 67.3^{\circ} \mathrm{S}$, $148.5^{\circ} \mathrm{E}$, or about $70 \mathrm{~km}$ east of the MGT) and an associated promontory of highly deformed fast ice to the east. These blocking features deflect pack ice away from the MGT [Massom et al., 2001a]. Until 2001 and 2002, the fast ice was also protected by two large grounded icebergs to the north [Massom, 2003].

[5] The Mertz Glacier drains approximately $83,000 \mathrm{~km}^{2}$ of the grounded East Antarctic Ice Sheet [Rignot, 2002] through two major ice streams. Its floating continuation, the MGT, extends $\sim 140 \mathrm{~km}$ from the grounding line and projects $\sim 100 \mathrm{~km}$ from the George V Land coast [Legrésy et al., 2004]. The MGT flows at a rate of about $1 \mathrm{~km} \mathrm{a}^{-1}$ [Berthier et al., 2003; Wendler et al., 1996; Wuite, 2006]. In recent years, it has shown signs of imminent calving, with the progressive widening, propagation, and recent joining of two major lateral rifts (marked in Figure 1). In this paper, we use satellite imagery (1973-2007) and satellite laser altimetry (2003-2008) to estimate the extent, age, and thickness of the MYFI and investigate the coupling between the MYFI and the MGT. Our observations suggest that the MYFI is mechanically coupled to the MGT and may enhance its stability, a factor which has previously been largely overlooked. We also analyze the impact of the MGT rifts and of large icebergs calved from the neighboring Ninnis Glacier tongue (150 km to the SE) on variability in MYFI distribution, with 
Table 1. Radarsat ScanSAR (1997-2004) and Envisat ASAR (2005-2007) Images Used in This Study

\begin{tabular}{lll}
\hline Year & \multicolumn{1}{c}{ Date } & \multicolumn{1}{c}{ Image } \\
\hline 1997 & 2 November & R1_10421_621 \\
1998 & 27 February & R1_12093_623 \\
1998 & 27 September & R1_15123_621 \\
1999 & 11 March & R1_17481_623 \\
1999 & 12 September & R1_20125_624 \\
2000 & 5 March & R1_22626_623 \\
2000 & 30 August & R1_25170_623 \\
2001 & 3 March & R1_27814_620 \\
2001 & 5 October & R1_30901_620 \\
2002 & 23 February & R1_32916_623 \\
2002 & 27 September & R1_36003_623 \\
2003 & 14 March & R1_38404_623 \\
2003 & 5 September & R1_40905_623 \\
$2004^{\mathrm{a}}$ & 24 October & R1_46836_621 \\
2005 & 8 March & $20050308 \_215735$ \\
2005 & 24 September & 20050924_221147 \\
2006 & 2 March & 20060302_221427 \\
2006 & 12 September & 20060912_221721 \\
2007 & 6 March & $20070306 \_221722$ \\
2007 & 7 September & 20070907_220312 \\
\hline
\end{tabular}

${ }^{a}$ The Radarsat images have the prefix R1. No suitable image is available for autumn 2004.

implications for the MGT. Taken together, these findings allow us to draw some important conclusions about the MYFI and its influence on the MGT, with implications for other regions of the coastal Antarctic Ice Sheet.

\section{Satellite Techniques and Methods}

\subsection{Satellite Imagery: Spatial Extent, Age, Rift} Mapping, and Velocity

\subsubsection{Spatial Extent and Age}

[6] We used a 10-year time series of calibrated satellite synthetic aperture radar (SAR) wide-swath (scanSAR) images from Radarsat-1 (1997-2005) and Envisat (2005-2007) to derive the spatial extent of the MYFI at the end of each austral summer (late February and March) and in austral spring (September and October). The SAR images (Table 1) were selected approximately 6 months apart to coincide with minimum and maximum sea ice (both fast and pack) extents. The extent was calculated by manually "masking" the region of interest on each image using ENVI software. At the SAR wavelength of $\sim 5.6 \mathrm{~cm}$ (C-band) and viewed in $\mathrm{HH}$ polarization, the MYFI is readily distinguishable from adjacent first-year pack and fast ice owing to its higher backscatter. This most likely results from changes in the ice salinity and microstructure with age and/or a strong contribution from the snow cover (under freezing conditions) [see Lubin and Massom, 2006, and references therein]. Multiple seasonal thaw-refreeze cycles and extended temperature-gradient metamorphism generally result in a snow cover on MYFI that is coarse-grained and contains icy layers up to a few centimeters thick, based on observations of broken out MYFI to the NE of the study region [Massom et al., 2001b]. We verified the SAR-derived MYFI spatial extents using time series of cloud-free NASA Moderate-Resolution Imaging Spectroradiometer (MODIS) visible images (250 m pixel size), acquired in March of each year (minimum sea-ice extent) and obtained from the U.S. National Snow and Ice Data Center [Scambos et al., 2001] and the NASA Level 1 Atmosphere
Archive and Distribution System (LAADS). We also obtained information on the extent of first-year fast ice from MODIS imagery acquired in September and October (maximum sea-ice extent). The MODIS images were processed using the MODIS Swath-to-Grid Toolbox (ms2gt) (T. Haran, The MODIS swath to grid toolbox, 2003, http://www.nsidc. org/data/modis/ms2gt) and ENVI software (ITT Visual Information Solutions, Boulder, Colorado, www.ittvis.com).

[7] We derived information on the age of the MYFI from Landsat Multispectral Scanner (MSS), Thematic Mapper (TM), and Enhanced Thematic Mapper+ (ETM+) imagery dating back to 1974 (Landsat imagery was obtained from the NASA Land Processes DAAC (https://lpdaac.usgs.gov/)). This information was supplemented with Soyuz Kosmos KATE200 imagery shown by Frezzotti et al. [1998].

\subsubsection{Rift Mapping}

[8] We examined the extent of rift features both within the MGT and MYFI (Figure 1) and their evolution over the 10 -year period in the SAR image sequence. SAR imagery was used in preference to MODIS imagery for this purpose, since rifts in the MYFI show up more prominently in the SAR images. ICESat elevation profiles (see section 2.2) provided information on elevations inside the rifts.

\subsubsection{Ice Motion}

[9] We estimated ice velocities for the MYFI and MGT through analysis of Radarsat ScanSAR images acquired on 2 November 1997 and 27 September 1998 (i.e., 329 days apart). This period was arbitrarily chosen to be representative of the time when the MYFI was fully intact. We used a modified image cross-correlation technique based upon the Image Correlation (IMCORR) technique originally developed by Scambos et al. [1992] to track persistent features in the SAR images across the MYFI slab and the eastern sector of the MGT. We chose a 10-month interval as this allows for more accurate determination of ice motion than shorter intervals. The images were co-registered to subpixel accuracy; details are given in the paper by Giles et al. [2009]. We derived maps of motion for the entire region (MYFI and MGT) with an estimated accuracy of $\leq 0.25$ pixels, where pixel size was $50 \mathrm{~m}$ for Radarsat and $75 \mathrm{~m}$ for Envisat. We also investigated the relative motion of the MGT and MYFI using SAR interferometry (InSAR) results from the ERS-1 and -2 Tandem Mission; details are given by Legrésy et al. [2004].

\subsection{Satellite Laser Altimetry: Ice Thickness}

[10] We derived information on ice thickness for both the MYFI and the MGT from selected surface elevation profiles measured by the Geoscience Laser Altimeter System (GLAS) onboard the Ice, Cloud and Land Elevation Satellite (ICESat). GLAS consisted of three pulsed near-infrared lasers that operated at $40 \mathrm{~Hz}$, resulting in range estimates to the surface at intervals of $\sim 172 \mathrm{~m}$ along track (when cloud is not present), which are converted to mean surface elevation over a laser footprint of 50 to $70 \mathrm{~m}$ [Schutz et al., 2005]. The estimated precision of retrieved mean surface elevations for sea ice is $\sim 2 \mathrm{~cm}$ [Kwok et al., 2004].

[11] ICESat was launched in January 2003 and since October 2003, following the failure of Laser 1, it has been operated in a "campaign mode" during which data have been acquired during the same 33-day subrepeat of a 91-day orbit two or three times per year. Campaigns are named Laser 2a, 
Laser $2 \mathrm{~b}$, and so forth. Laser $2 \mathrm{a}$ lasted for 55 days, so data acquired during the first 22 days were not repeated. For each campaign, we obtained parameters from Release 428 of the GLA12 product, which was the highest-quality complete release available at the time of analysis. We converted the GLA12 geolocated footprint positions (latitude, longitude, and elevation) from the TOPEX/Poseidon ellipsoid to the WGS-84 ellipsoid. Following Fricker and Padman [2006], we used the gain and energy parameters to select passes that were unaffected by clouds and generally discarded repeats for which gain was $>30$. Release 428 ICESat elevation data are routinely corrected for ocean and load tide using the TPX07.2 model, which is not accurate around Antarctica; therefore, we "retided" the GLA12 elevations, i.e., added back the applied tide corrections. We also applied the saturation correction to the elevations. For the GLAS 1064 nm altimeter channel, high laser return energy combined with the inability of the automatic gain control to adjust below its preset lower limit causes detector saturation. High return energy overloads the detector, leading to distorted waveforms that are clipped and artificially wide. For such waveforms, ICESat's standard Gaussian fit processing is biased toward longer ranges, leading to low elevation estimates [Abshire et al., 2005].

[12] To estimate the MYFI thickness, we selected single acquisitions of three ICESat ground tracks that cross the study region, namely Tracks 1170, 165, and 307 (see Figure 1 for their location). Track 1170 was only acquired during the Laser 2a campaign (October and November 2003) and was not repeated. For the other two tracks, we used data from the Laser 3 g campaign (October and November 2006). By using data from the same season (i.e., the austral spring), we hope to have minimized any seasonal signal in MYFI thickness.

[13] We converted ICESat-derived elevation to ice freeboard using the mean elevation of areas of open water and thin sea ice on the western side of the MGT (identified in the SAR imagery) as a (zero) reference level, following Fricker et al. [2005] and Scambos et al. [2008, 2009]. To account for the effects of tides, the geoid, and mean dynamic sea surface topography, we assumed that tidal amplitude was the same on both sides of the MGT and calculated a reference level for the fast-ice area on the eastern side of the MGT by applying a geoid-slope correction using the EGM2008 geoid model (http://earth-info.nga.mil/GandG/wgs84/gravitymod/ egm2008/egm08_wgs84.html).

[14] Estimation of fast ice thickness $Z_{F I}$ was based upon ICESat measurements of ice freeboard elevation $F$ and a number of assumptions about fast ice density $\rho_{I}$ and the density $\rho_{S}$ and depth $Z_{S}$ of the overlying snow cover (in situ data are not available for this remote region). Given that the laser signal does not penetrate the snow cover, $F$ refers here to the total (combined) elevation of the fast ice plus snow above the ocean surface. According to the hydrostatic relation and following Zwally et al. [2008], $Z_{F I}$ was then related to $F, \rho_{I}$, $\rho_{S}$, ocean water density $\rho_{W}$, and $Z_{S}$ such that

$$
Z_{F I}=\frac{\rho_{W}}{\rho_{W}-\rho_{I}} F-\frac{\rho_{W}-\rho_{S}}{\rho_{W}-\rho_{I}} Z_{S}
$$

Assuming constant values of $\rho_{W}=1028 \mathrm{~kg} \mathrm{~m}^{-3}$ [after Williams et al. [2008] and B. Galton-Fenzi, personal communication, June 2010], $\rho_{I}=850 \mathrm{~kg} \mathrm{~m}^{-3}$ (a mean value for mainly multi-year pack ice in the Arctic given by Spreen et al.
[2006]) and $\rho_{S}=360 \mathrm{~kg} \mathrm{~m}^{-3}$ (the latter based on mean Antarctic values presented by Massom et al. [2001b]), and that the ice is in hydrostatic equilibrium, $Z_{F I}$ can then be expressed as follows:

$$
Z_{F I}=5.775^{*} F-3.753{ }^{*} Z_{S}
$$

Since we have no knowledge of the true MYFI density, we also compute $Z_{F I}$ for a sea-ice density of $915.1 \mathrm{~kg} \mathrm{~m}^{-3}$, which is the value used by Zwally et al. [2008]. This results in the relationship:

$$
Z_{F I}=9.105^{*} F-5.917^{*} Z_{S}
$$

Implicit in equations (1)-(3) are the assumptions that the snow cover is dry and that there is a distinct interface between the ice and snow, i.e., the snow-ice interface is not below sea level and is not flooded. Both are reasonable assumptions in this case. Snow-depth estimates from satellite AMSR-E data are not used here, as the upper limit for snow depth retrievals is $0.5 \mathrm{~m}$ [Comiso et al., 2003] and the current algorithm also significantly underestimates depth in certain circumstances [Massom et al., 2006; Worby et al., 2008a]. We use a constant value of $Z_{S}=1 \mathrm{~m}$, based upon earlier observations of broken out (drifting) MYFI in the MGT region [Massom et al., $2001 \mathrm{~b}$. However, this will result in approximate estimates of MYFI thickness only as equations (2) and (3) are sensitive to $Z_{S}$, and no accurate information is available on snow accumulation and compaction rates.

\section{Results and Discussion}

[15] The results of our multisensor analysis cover many aspects of the MYFI and the MGT, and we present them in the following order: MYFI age, MYFI extent, MYFI thickness, MGT/MYFI velocities, and rift propagation.

\subsection{Age of the MYFI}

[16] Historical Landsat imagery dating back to 1974 provided us with the best approximation of the MYFI age. A Landsat-1 MSS scene (Path 086, Row 108) acquired on 7 February 1974 (not shown) shows that MYFI was absent from the bay at the southeast corner of the MGT at that time. This sets a maximum limit on the age of the fast ice of 35 years. In addition, there appears to be no indication of the presence of large icebergs in the area in 1974, supporting the link between iceberg presence and the formation of the MYFI. While there is a cloud cover over the area, it is possible to discern the outline of the Mertz Glacier Tongue, and the area to the east of the tongue appears to be open water with no indication of a large mass of ice as sea ice or icebergs. A Soyuz Kosmos KATE200 image acquired on 14 February 1984 shows a complete cover of fast ice between the MGT and the Ninnis Glacier to the east, bounded to the north by four icebergs that had calved from the Ninnis Glacier [Frezzotti et al., 1998, Figure 5]. A Landsat-5 TM image (Path 082 Row 107) acquired on 2 January 1989 (Figure 2a) shows that the cover of fast ice to the east of MGT was still present and was bounded to the north by the two largest icebergs. Two icebergs that were in the north in 1984 had moved away, and the two large icebergs had moved west and north. 

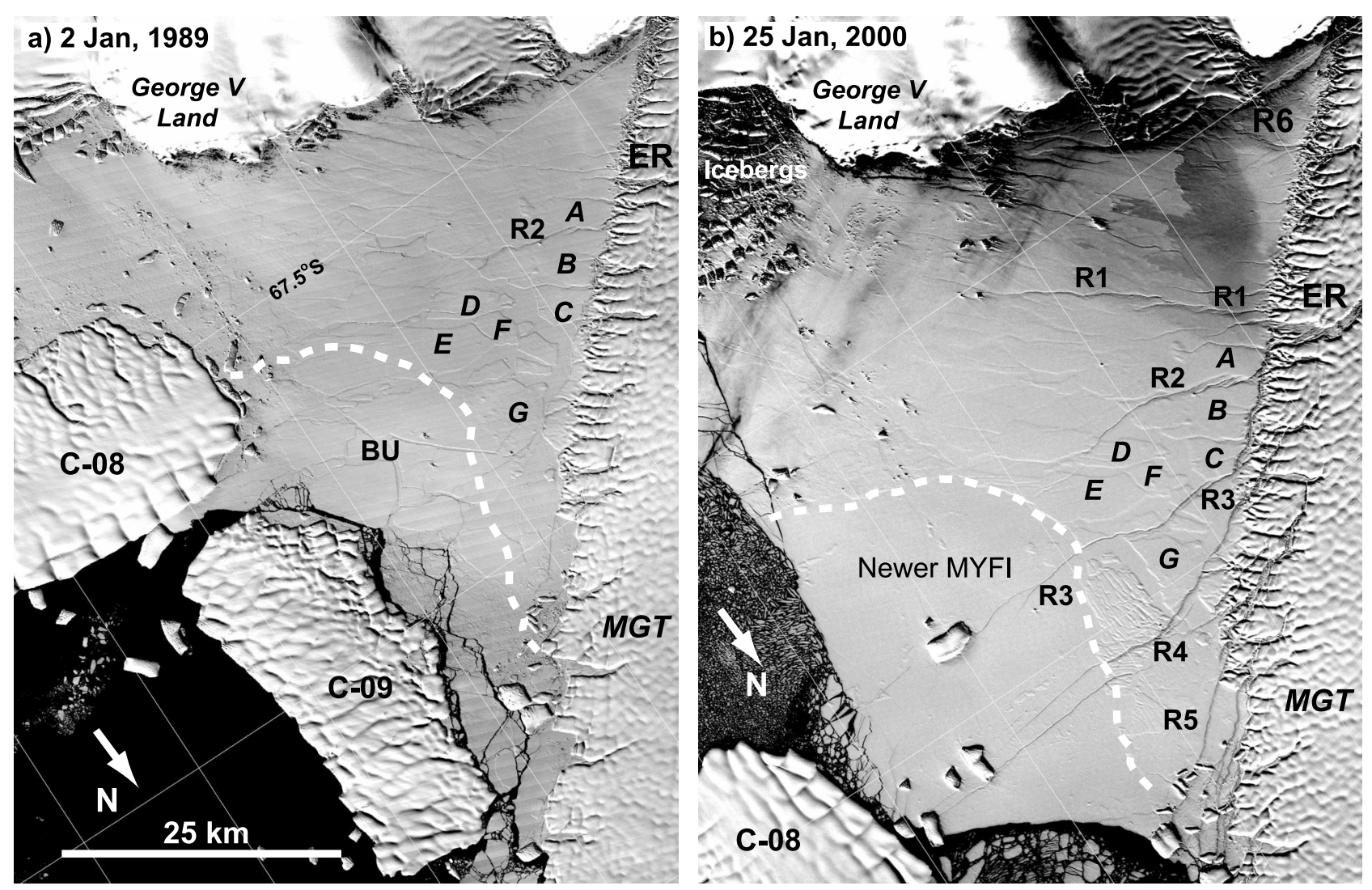

Figure 2. Details from satellite images of the MYFI and the eastern flank of the MGT: (a) Landsat-5 TM image (Path 082, Row 107) from 2 January 1989 and (b) Landsat-7 ETM+ image (Path 082, Row 107) from 25 January 2000. R1-R6 denote rift features equivalent to those marked in Figure 1, and ER indicates the eastern rift of the MGT. The white dashed line in Figure 2a denotes the approximate southern limit of very old and thick MYFI that subsequently broke out following the northward drift of icebergs C-08 and C-09, while that in Figure $2 b$ denotes the approximate boundary of newer MYFI that subsequently formed.

[17] A Landsat-5 TM image from 1989 (Figure 2a) shows that the fast ice cover was a two-component system at that time. The main component, which covered most of the area, comprised many segments of thick fast ice that resembled pieces of a jigsaw puzzle that had been disturbed but not dispersed. Most segments retained their approximate relative relationship with their neighbors within the matrix. A few segments were still attached to the eastern margin of MGT. The second component comprised ice that formed in the gaps between the segments, welding the whole matrix into one unit. Along the southern coastal margin, there were narrow areas of open water, where the fast ice was carried away from the coast by the motion with the MGT. The nature of the edges of the fractures in the body of the ice nearer the coast suggests that this ice was thinner than that farther north. The edges were sharp compared to those farther north, where the edges appeared to be softer, such as can be expected from gradual build of snow, plus the length of the shadows indicate different thicknesses.

[18] Comparison of the 1989 and 2000 Landsat images (Figures $2 \mathrm{a}$ and $2 \mathrm{~b}$ ) and subsequent imagery (not shown) reveals that many of the structural elements of the matrix that had formed earlier were preserved in the later fast ice cover (to the present). The drift of the Ninnis bergs C- 08 and C-09 to a position adjacent to the MGT led, however, to a shearing and breakout of the northeastern part of the old (first) component, i.e., within the approximate area marked BU in Figure 2a. This left an open area where fast ice could reform to produce a third component, namely, newer MYFI (Figure 2b). Recently formed fractures crossing the current fast ice cover passed through elements of all components of the matrix, again suggesting that the matrix was acting as a continuous unit.

[19] From this history, we expect that the current MYFI cover has varying thicknesses, depending upon the age of the components. The shadowing and highlights present along the component edges in the Landsat images indicate that the older component was then already thick ice by 1989 (Figure 2a). It is probable that it was at least 10 years old by then, and at most 15 years old. As such, the current MYFI cover consists of (1) an older component that is at least 25 years old, probably 30 years and at most 35 years old; (2) a secondary component that is at least 20 years old; and (3) a third component that is less than 20 years old. Component (3) shows up as a darker region in the SAR image in Figure 1.

\subsection{Spatial Extent of the MYFI}

[20] Comparison of the sequence of images acquired at approximately 6-monthly intervals from 1997-2007 (see Figure 3 for some examples) supplemented with MODIS imagery and a time series of estimated MYFI area over this 

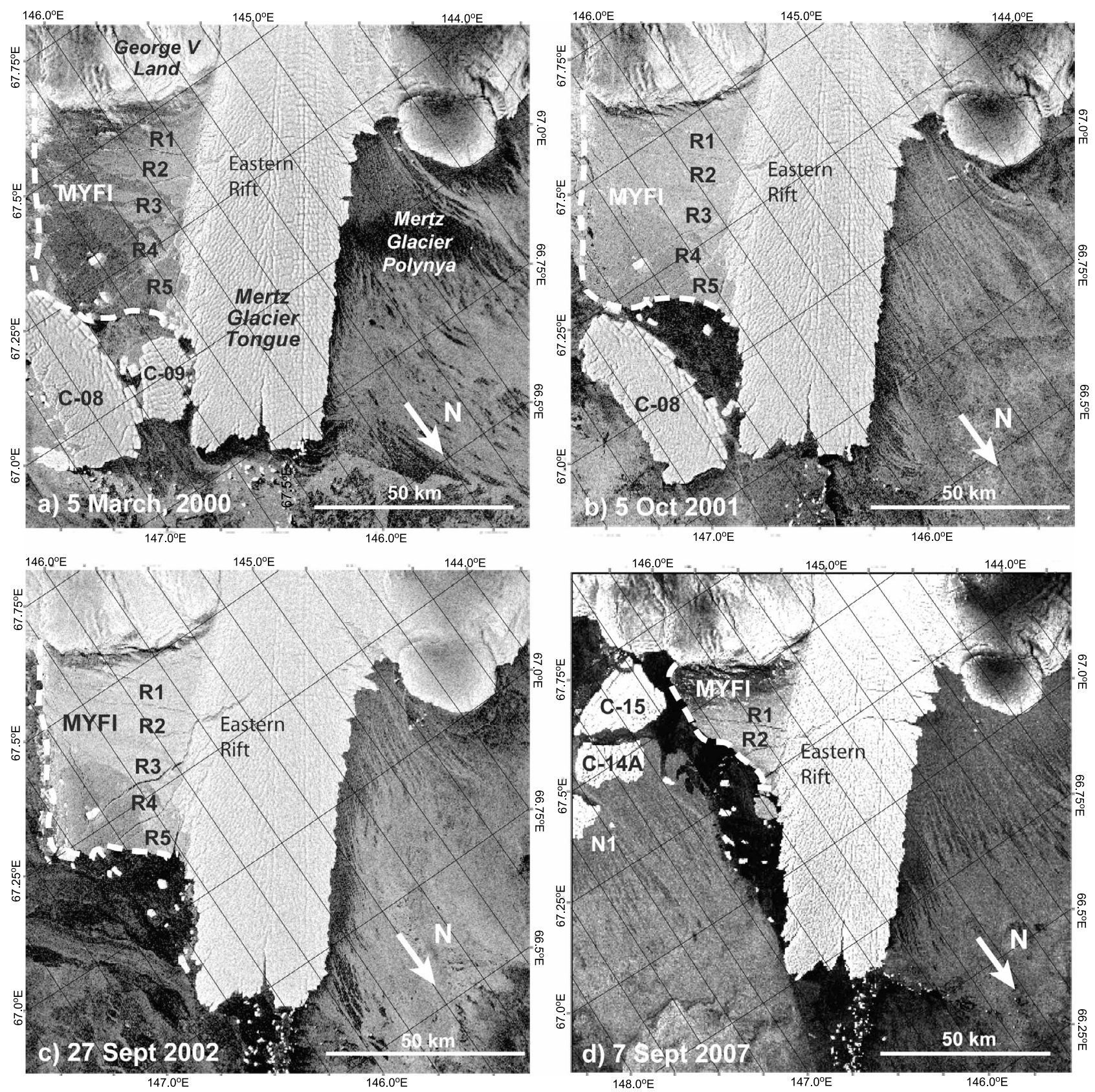

Figure 3. Sequence of SAR images from Radarsat for (a) 5 March 2000, (b) 5 October 2001, and (c) 27 September 2002 and Envisat for (d) 7 September 2007, showing the area extent of the MYFI when icebergs C-08 and C-09 were present (Figures 3a and 3b) and its decline following the departure of these icebergs (Figures $3 \mathrm{c}$ and $3 \mathrm{~d}$ ). Approximate boundaries of the MYFI are marked with the dashed line. Here we take the approximate eastern boundary of MYFI to be the line of small icebergs marked in Figure 1. Note that the scale of Figure 3d is different to include locations of icebergs N1, C-14A and C-15. Radarsat imagery ONASA/Canadian Space Agency, Envisat imagery OESA.

time period (Figure 4) reveal that the MYFI extent was at a maximum in 2002, and there has since been a significant reduction. A number of phases are apparent in the following time series: (1) 1997 to late 2001, a period of relative stability with extent around $2000-2100 \mathrm{~km}^{2}$; (2) 2002, a decrease of $\sim 150 \mathrm{~km}^{2}$ immediately following the ungrounding/departure of C-08; (3) 2002 to early 2005 , a significant decrease from approximately 2000 to $1200 \mathrm{~km}^{2}$; (4) early 2005 to late 2006 , a stable period during which the area of MYFI increased slightly as it moved forward with the MGT; (5) late 2006 to early 2007 , a decrease by almost $250 \mathrm{~km}^{2}$; and (6) 2007, an extent of $\sim 950 \mathrm{~km}^{2}$.

[21] We propose that the reason for changes in MYFI extent is linked to the presence of grounded tabular icebergs in the region. Two such icebergs, designated C-08 and C-09, calved from the Ninnis Glacier tongue in 1980-1982 before grounding at the NE tip of the MGT in 1989-1991 [Frezzotti et al., 1998]. While these bergs were grounded, they formed 


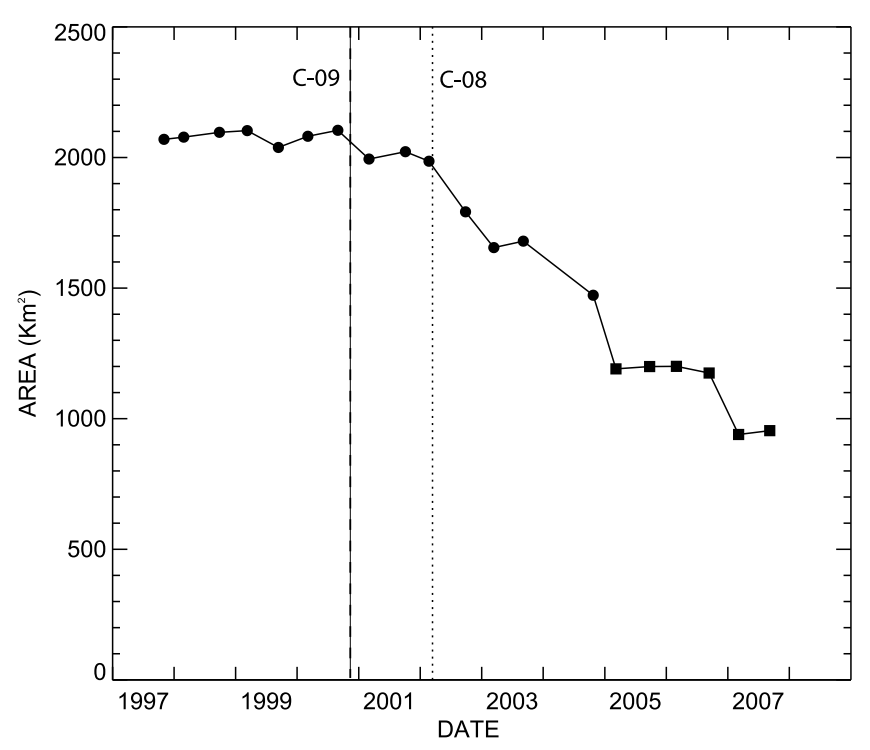

Figure 4. Area extent of MYFI determined from analysis of twice-yearly SAR imagery (February/March and October/ November) from 1997-2007. The vertical lines denote the timing of the ungrounding and departure of icebergs C-09 and $\mathrm{C}-08$.

pinning points for the MYFI slab at its northern boundary, and the MYFI slab extended along most of the length of the MGT eastern margin. As well as by providing mechanical stability, the bergs may have contributed to the growth of the MYFI by modifying the local ocean circulation as discussed in section 3.3. The bergs ungrounded and drifted away in November 2000 (C-09) and January 2002 (C-08) [Massom, 2003]; the rapidity of MYFI recession after they drifted away is shown in Figure 4. The major southward recession of the MYFI front occurred after the ungrounding of C-08; the area extent of the MYFI attached to the MGT was reduced by more than half in the 5 years that followed. We believe that the recession of MYFI relates to removal of the iceberg pinning points, which also acted as protective "buffers" (see also the studies by Rémy et al. [2008] and Brunt et al. [2006] in the Ross Sea). This exposed the MYFI to destructive open-ocean conditions (particularly at minimum pack ice extent in summer). Ocean waves are a key contributor to the breakup of Antarctic fast ice in unprotected Antarctic coastal regions [Crocker and Wadhams, 1989; Langhorne et al., 2001].

[22] Both icebergs continued to have an influence of annual fast ice (AFI) distribution for a few months after ungrounding from the immediate NW of the MGT by temporarily regrounding at the tip of the line of grounded small icebergs extending northwestward from the tip of the glacier tongue [Massom, 2003].

[23] On the decadal scale, it is possible that icebergs that calve from the Ninnis Glacier tongue ( $\sim 150 \mathrm{~km}$ away) have a regular impact on MGT: three more large bergs calved in 2000-2002 [Massom, 2003] look set to take the place of C-08 and C-09 (marked N1, C-14A, and C-15 in Figure 3d). This could enable the MYFI extent to regenerate to its pre-2002 extent, once again engaging much of the eastern flank of the MGT, assuming that a major calving of the MGT has not occurred in the interim.
[24] The southward recession of the MYFI edge decreased the proportion of the eastern flank of the MGT affected by MYFI attachment. In 1997, the MYFI adjoined $\sim 64 \mathrm{~km}$ of the eastern margin of the MGT, compared to a distance from coast to terminus of $93 \mathrm{~km}$. By September 2007, this proportion had diminished to $\sim 50$ of $\sim 103 \mathrm{~km}$ and the northern margin of the MYFI had regressed toward the major eastern rift on the MGT (Figure 3). On 5 March 2000, it extended $\sim 43 \mathrm{~km}$ to the north of the rift, but only $18 \mathrm{~km}$ by 7 September 2007. In March 2009, the thick fast ice still fully enclosed the major eastern rift on the MGT. The exact timing of exposure of the eastern major rift to open ocean conditions in summer is difficult to predict, as is the timing of the MGT calving and its impact on the MYFI slab.

[25] Although the area of MYFI has decreased significantly since late 2001, the eastern flank of the MGT that is seaward of the MYFI still has annual fast ice (AFI) attached to it each year from autumn through spring (Figure 5). This much thinner AFI cover typically attaches itself not only to the MGT but also to a line of smaller grounded icebergs (marked GB1 in Figure 5) directly seaward of the glacier terminus. Owing to the local bathymetry, the AFI can hold ungrounded icebergs in place, i.e., prevent the drift of ungrounded icebergs [Massom, 2003], so it possibly also plays a role in stabilizing the ice tongue for part of the year, supplementing the much thicker MYFI, which is locked onto the landward part of MGT more permanently. Work is in progress to determine whether this AFI cover has changed in extent in recent years. On decadal scales, a factor affecting this is the potential impact of both changes in glacier discharge rates and oceanic conditions, e.g., the possible southward incursion of relatively warm modified circumpolar deep water [Marsland et al., 2004]. The latter could have a major impact on iceberg basal melt and ungrounding-grounding behavior. Improved information is also required on the regional bathymetry.

\subsection{Thickness of the MYFI}

[26] ICESat-derived elevation and thickness profiles for the three selected ICESat passes across the MYFI are presented in Figure 6, with track locations shown in Figure 1. Two characteristics of the MYFI are apparent in these examples, and these features are seen in all available ICESat tracks for the region (including repeat acquisitions along these tracks): (1) an increase in MYFI thickness from the coast outward toward the MGT, and (2) a significant and steep "ramping up" in thickness in a narrow band (up to about $5 \mathrm{~km}$ wide) immediately adjacent to the MGT (marked RU on profiles in Figure 6). In this band, the large elevation increase (up to $\sim 11 \mathrm{~m}$ ) may be due in part to enhanced snow accumulation alongside the MGT as well as debris from the glacier. Derived thickness values for the MYFI (excluding the thicker inner band) range from $\sim 10-35 \mathrm{~m}$ (for $\rho_{I}=850 \mathrm{~kg} \mathrm{~m}^{-3}$ ) and $\sim 15-55 \mathrm{~m}$ (for $\rho_{I}=915.1 \mathrm{~kg} \mathrm{~m}^{-3}$ ). These thickness values are similar to those obtained for the MYFI linking the StancombWills Ice Tongue and the Brunt Ice Shelf, where estimates were up to $50 \mathrm{~m}$ [Humbert et al., 2009]. The thickness of the MGT to which it is attached ranges from $\sim 600 \mathrm{~m}$ in the south to $\sim 300 \mathrm{~m}$ in the north [Legrésy et al., 2004]. For comparison, AFI adjoining to the southeast (marked AFI in Figures 1 and $6 c$ ) is much more uniform in surface elevation and substantially thinner, i.e., of the order of 3.25-5.2 m maximum 


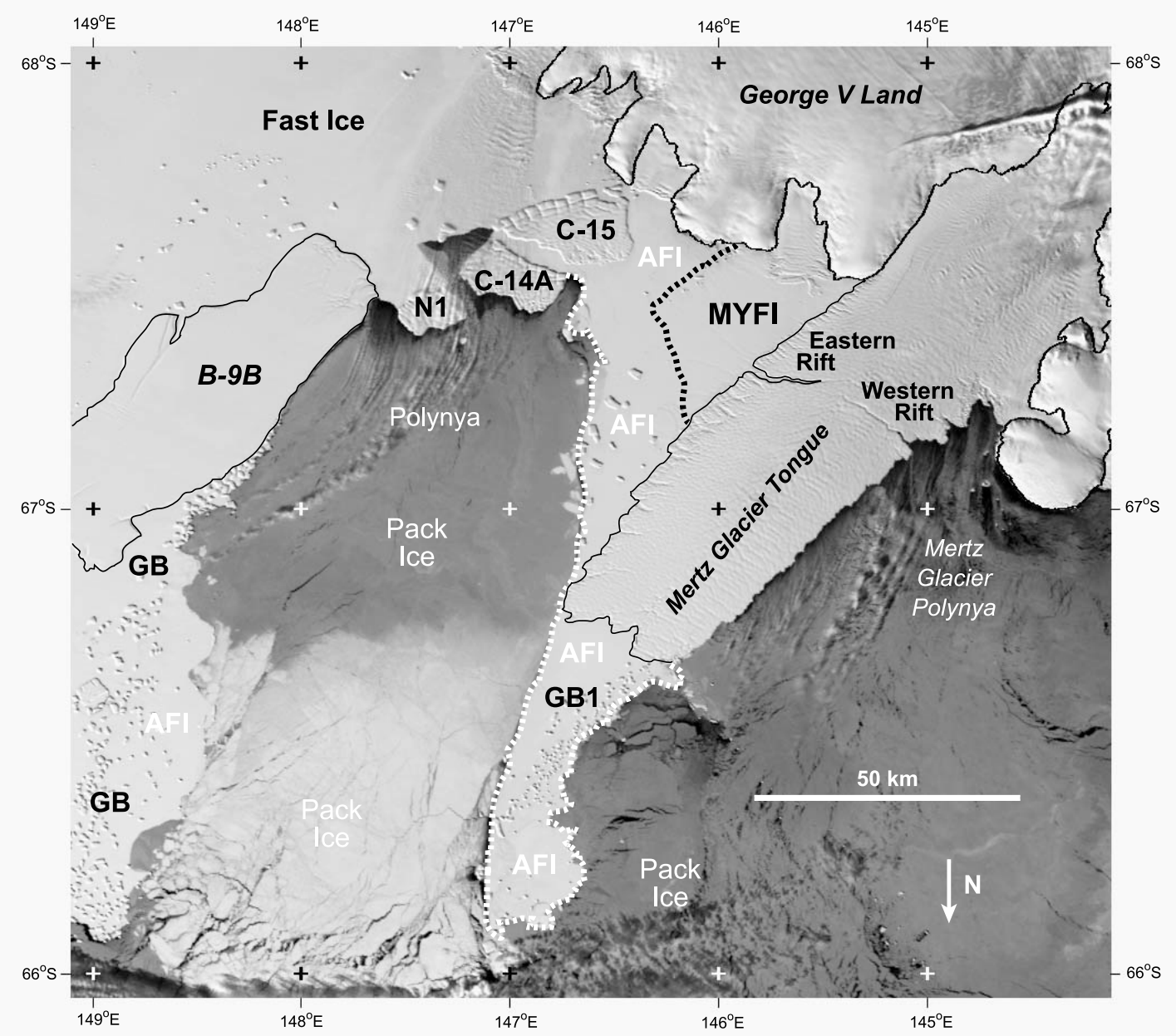

Figure 5. MODIS visible image from 2 September 2007 showing the extent of AFI locked onto the eastern margin of the MGT (within the white $b$ line), to encompass the MYFI slab [area extent at this time shown by the black dashed line). Icebergs calved from the Ninnis Glacier in 2000 are marked N1, C-14A, and C-15. GB1 is the line of grounded icebergs.

(depending again on the ice and snow densities used). The mean thickness of first-year pack ice in East Antarctica is $\sim 0.7 \mathrm{~m}$ [Worby et al., 2008b]; the MYFI slab is an order of magnitude thicker than this.

[27] Uncertainties in the thickness estimate of ICESatderived MYFI fast ice arise from several sources: (1) errors in ice and ocean density, (2) errors in snow depth (accumulation and compaction rates) and density, (3) ICESat instrumental errors, (4) errors in the geoid, and (5) errors in the mean dynamic topography of the ocean; (4) and (5) have been minimized, however, because we leveled to open ocean on each pass. Given the lack of independent information on these variables, it is difficult to make a formal error estimate. Nevertheless, the ICESat-derived fast ice thicknesses presented here provide a first approximation of the thickness of the MYFI and show that it is an order of magnitude thicker than the nearby annual fast/pack ice. They also confirm that there are different sets of thicknesses across the MYFI, as we expected from the age analysis.

[28] The derived thickness of the MYFI is surprising and cannot be explained by simple thermodynamic freezing of seawater alone, because congelation ice growth (due ultimately to atmospheric heat loss) is limited by the low heat conduction through thick fast ice. This implies that there must be another mechanism through which the MYFI grows. Accordingly, we hypothesize that basal accretion of marine ice [Oerter et al., 1992] may play an important role in the growth of MYFI. Marine ice is formed by the deposition of frazil ice crystals produced in suspension when ice shelf water (ISW) originating from ice-ocean interaction deep in subice cavities [e.g., Robin, 1979; Lewis and Perkin, 1986; Souchez et al., 1991] becomes supercooled as it rises toward the ice front. Marine ice, sometimes accreted over hundreds of years, is found under several Antarctic ice shelves in bands of 

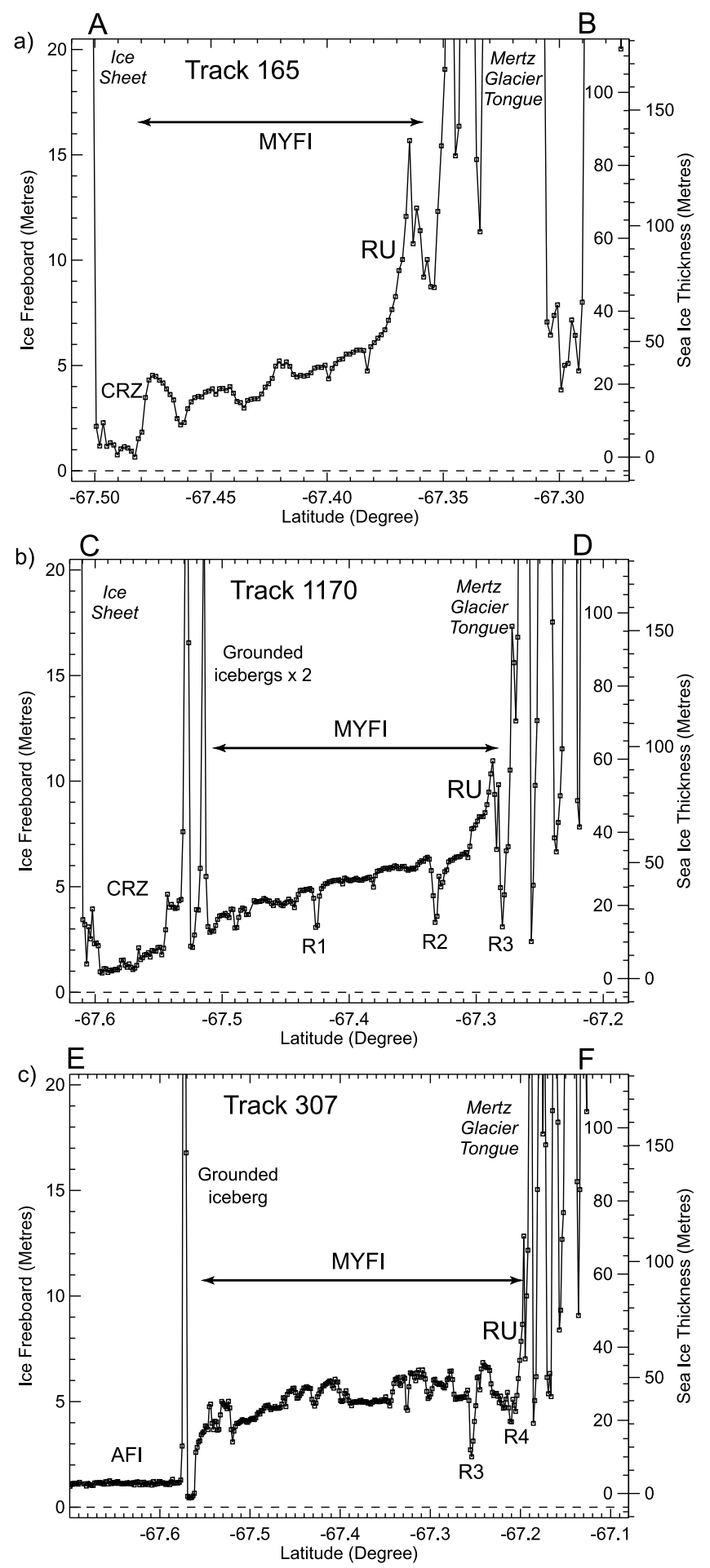

Figure 6. Profiles of ice freeboard elevation $(F)$ and estimated fast ice thickness $\left(Z_{F I}\right)$ derived from ICESat GLAS data acquired over the MYFI slab from (a) Track 165 on 10 November 2006, (b) Track 1170 on 9 October 2003, and (c) Track 307 on 19 November 2006. On the right-hand $y$-axis (ice thickness), the scale on the left corresponds to values derived from ICESat elevation data using equation (2), while that on the right is derived using equation (3). Features referred to in the text are marked, while other features marked correspond to those in Figure 1. Letters above each plot refer to the segments marked in Figure 1. substantial thickness (up to several hundred meters) [e.g., Oerter et al., 1992; Fricker et al., 2001; Lambrecht et al., 2007; Holland et al., 2009].

[29] Modeling by Grosfeld et al. [2001] of ice-ocean interaction under the Filchner Ice Shelf demonstrated that circulation and sea-ice formation were sensitive to the presence of grounded bergs near the ice shelf from a major calving event and indicated that ISW rising at the front of the ice shelf could lead to generation of a considerable fast ice tongue, with modeled accretion rates of up to 4 meters per year. Their study raises the possibility that the presence of the large icebergs and the extent of the MGT may influence the circulation of ISW and any marine ice contribution to the MYFI in the present case. It is not known whether there is any marine ice deposition under the MGT, but substantial basal melting has been inferred near the deep grounding line of the Mertz glacier [Rignot, 2002], leading to the expectation that ISW is produced, and ISW has been observed emerging from the western edge of the MGT [Williams and Bindoff, 2003].

[30] If marine ice accretion is occurring beneath the MGT, then it is plausible that it would persist into the MYFI zone and strengthen the bond between the MGT and the MYFI. These hypotheses require further testing through modeling and observation (work that is currently underway [B. GaltonFenzi, personal communication, December 2009]). If the MYFI grows through marine ice accretion, this has implications for the stability of the MYFI in a warming ocean, since (1) the existence of marine ice depends on the subice shelf circulation, which would change with ocean conditions; and (2) marine ice is thought to be vulnerable in a warming ocean owing to its porous nature [Craven et al., 2009; Khazendar et al., 2009]. Moreover, knowledge of the marine ice thickness is required to more accurately compute MYFI thickness, as it has a higher density. Marine ice accreted beneath the Amery ice shelf has an effective density considerably greater than typical sea-ice or even glacial ice of meteoric origin, averaging $936 \pm 26 \mathrm{~kg} / \mathrm{m}^{3}$ [Craven et al., 2009], largely due to its porosity when initially deposited as frazil platelets. The uncertainty regarding marine ice density complicates the estimation of the total thickness of the MYFI from buoyancy.

\subsection{MGT and MYFI Ice Motion}

[31] SAR-derived displacements for the MYFI and the adjacent margin of the MGT are shown in Figure 7a, colorcoded by location. The time interval was arbitrarily chosen to reflect the drift regime of both ice masses. In Figures $7 \mathrm{~b}$ and $7 \mathrm{c}$, we present a plot of $x$ - and $y$-components of the MGT and MYFI ice displacements. The $x-y$ axes are simply the vertical and horizontal axes of the plots in Figure 7a. This is arbitrary with respect to latitude and longitude, but was chosen to place the mean center line of the Mertz glacier tongue movement (over an early subset of images in Table 1) to be coincident with the plot vertical axis $(y)$. Apart from placing the tongue in a suitable orientation for display, this also allows deflections of the tongue (to the left or right) to be expressed as $\pm x$ displacements about $x=0$. For the locations over the MGT, the color scheme changes from blue to light green linearly with the $y$ position, i.e., essentially from south to north and reflecting distance from the coast. Although this changing color also approximates the increasing flow velocity of the MGT after exiting its coastal constriction, the color gradation is used here merely to enable the corresponding vectors to 

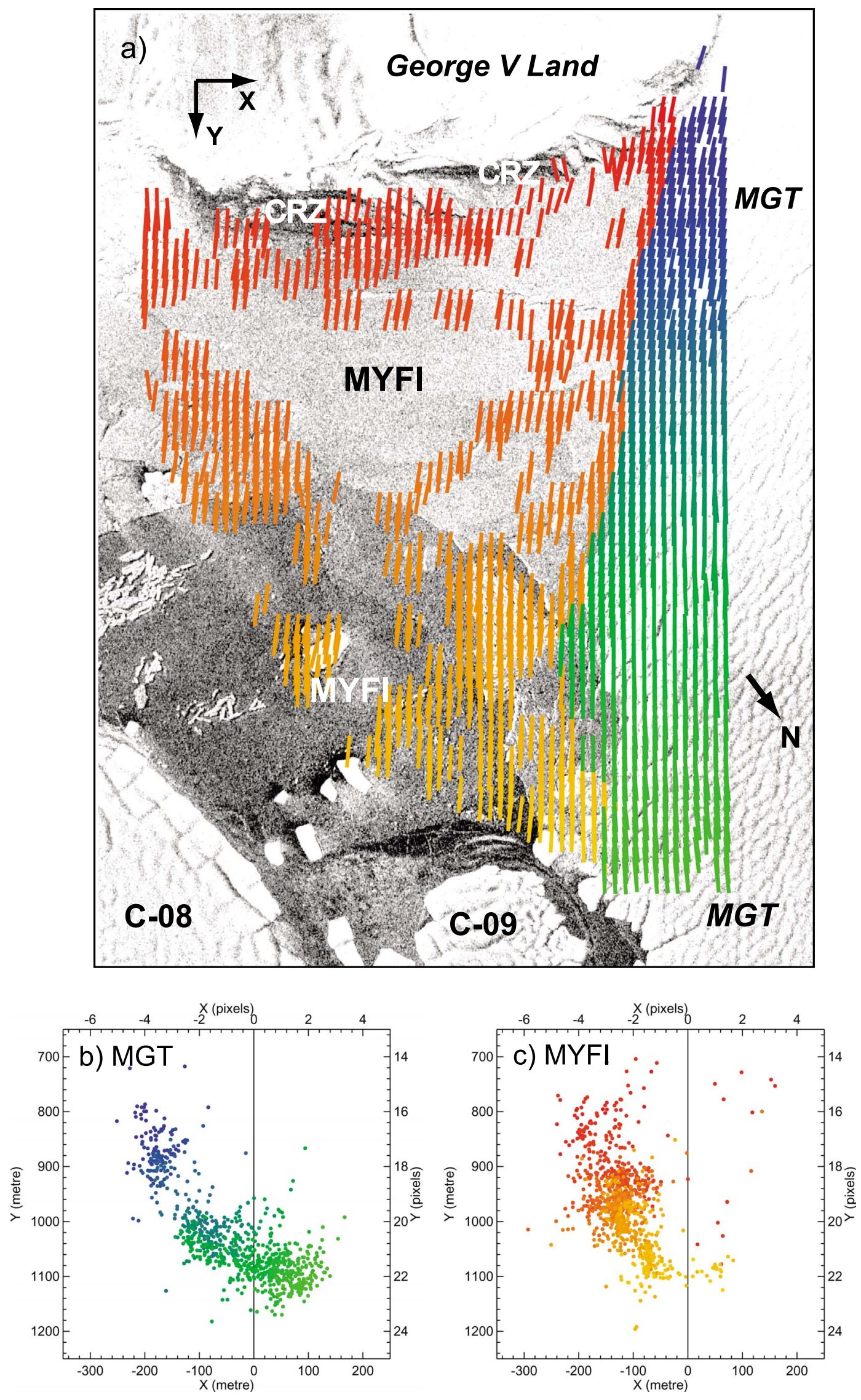

Figure 7 
bevisually located on the corresponding scatterplots in Figure $7 \mathrm{~b}$. Over the MYFI, the coloring changes in a similar fashion with increasing $y$ position, i.e., from dark red to light orange (Figure 7c).

[32] The displacements for both the MGT and MYFI occupy roughly the same region within the $x-y$ displacement ranges on the plots, reflecting the high common velocity, but they are displaced some 20 pixels from the zero registration point (not shown). The tight scatter grouping that defines the zero point comprises low displacement IMCORR matches obtained within near-zero velocity reference "tie regions" on the continental ice (see Giles et al. [2009] for details). The substantial similarity of the two displacement clusters confirms that the MYFI is locked onto the MGT (see also Wuite [2006]) and deforming with it. In particular, the MYFI speeds up in the same way as the MGT the farther offshore it is. This explains the set of rifts that occur across the MYFI, since the latter would not of itself naturally deform in quite the same way as the massive and thick MGT ice structure. Rather, the western margin of the MYFI slab is stretched and stressed owing to its attachment to the stretching MGT, while its remaining boundaries are essentially stress-free, except where the slab is locked to grounded icebergs.

[33] That the MYFI matrix was moving as a single slab and in tandem with the eastern margin of the MGT is confirmed by the movement of thick (old) MYFI structural elements shown in Figures 2a-2g. Between 1989 and 2000, these elements moved en masse (with minimal apparent deformation). Moreover, elements directly adjacent to the MGT, i.e., A-C in Figure 2, remained directly alongside the same points on the glacier tongue margin, again suggesting that the MFYI and MGT were connected and moved together.

[34] The continuous velocity field results across the MGT and the MYFI suggest a strong mechanical coupling between them. The eastern margin of the MGT and the thick MYFI attached to it both advance northeastward together at a rate of approximately $1 \mathrm{~km}$ per year. This rate is consistent with previous estimates of the ice tongue velocity [Wendler et al., 1996; Berthier et al., 2003]. Although the basic MYFI linear movement trend described here is perpetuated over the entire SAR data set, later motions are complicated by a deflection of the MGT (see R. A. Massom et al., Impact of grounding, fast ice and iceberg collisions on the changing dynamics of the Mertz Glacier Tongue, East Antarctica, manuscript in preparation, 2010), which introduces an additional pivoting motion.

[35] The strong degree of mechanical coupling or continuity between the MYFI and the MGT is further illustrated using interferometric (InSAR) analysis of a suitable SAR image pair from the ERS-1 and ERS-2 Tandem Mission (in this case from 28 and 29 May 1996) and by comparing the resultant interferogram with a contemporary SAR amplitude image. Results are shown in Figure 8. The fringe pattern shows the strain on the various parts of the glacier tongue, the MGT-MYFI transition, and the MYFI. Confirmation of the strong mechanical link between the MYFI and MGT comes from the fact that there is a continuous fringe pattern (i.e., no significant discontinuity) at the transition between the two ice masses. In contrast, an obvious discontinuity occurs around the eastern rift. Furthermore, the fringe pattern is disrupted between the main body of MYFI and the Antarctic coast (in the vicinity of the area marked CRZ in Figure 8), indicating a lack of coupling there.

[36] Over the glacier tongue, a large transverse strain comes from the spreading of the thick $(\sim 400 \mathrm{~m}$ at this location [Legrésy et al., 2004]) floating ice. This is well captured by the interferogram (with some complications around the Eastern rift), since the view direction (perpendicular to the edge of the image shown in Figure 8) is almost directly across the MGT. The MYFI does not thin and spread as strongly as the glacier, since, while it is thick compared to typical fast ice, it still has much lower gravitational stresses than the MGT, and indeed the strain pattern of the MGT does not extend into the MYFI. Given the strong mechanical link between the glacier and the fast ice, the whole MYFI slab will be translated to the northeast by the motion of the MGT. We can expect that, owing to the cohesion of the MYFI to the MGT, the longitudinal straining of the MGT is transmitted to the MYFI along their common border, setting up stresses in the MYFI.

[37] While the southeastern extremity of the MYFI is in contact with the coast, the seaward dragging of the fast ice by the advancing MGT constantly opens up a gap between fast ice and the coast, which we refer to as the Coastal Regeneration Zone (CRZ; shown in Figures 1, 7a, and 8). Regeneration of fast ice in this band presumably occurs by rapid thermodynamic growth, with icebergs calved from local glaciers also becoming incorporated into the MYFI. The thickness contrast between the CRZ and the MYFI to the north is apparent in Figures $6 \mathrm{a}$ and $6 \mathrm{~b}$, with much lower values in the CRZ that range from about 0.3 to $6.0 \mathrm{~m}$ (taking $\rho_{I}=850 \mathrm{~kg} \mathrm{~m}^{-3}$ ) or about $0.5-9.5 \mathrm{~m}$ (taking $\rho_{I}=915.1 \mathrm{~kg} \mathrm{~m}^{-3}$ ). Even these values may be an overestimate owing to the possible accumulation of substantial snow in the form of spin-drift blowing seaward off the ice sheet in strong katabatic winds.

\subsection{Rift Propagation Through the MYFI}

[38] Analysis of the 10-year SAR image sequence revealed a series of six major longitudinal rifts emerging along the eastern flank of the MGT that continue into the MYFI (Figure 3; rifts are marked R1-R6 in Figure 1). Rifts R1-R3 propagated through the MYFI from the major eastern rift on the MGT, while rifts R4-R6 emanated from smaller rifts along the eastern side of the MGT. The propagation of these rifts into the MYFI, and the persistence/continuity of their structure, provides further evidence supporting the strong

Figure 7. (a) Radarsat ScanSAR image from 2 November 1997 of the MYFI slab and adjoining MGT showing satellitederived ice motion vectors for the interval between that date and 27 September 1998. The vector lengths are correct in orientation and relative lengths, but the actual scale is arbitrary. (b) An $x-y$ scatterplot of displacements over the eastern part of the MGT shown in Figure 7a, with cluster colors corresponding to the colors of vectors in Figure 7a. (c) An $x-y$ scatterplot of displacements over the MYFI shown in Figure 7a, with cluster colors corresponding to the colors of vectors in Figure 7a. The displacements are the actual values over the 329-day interval between images. SAR imagery CNASA/Canadian Space Agency. 

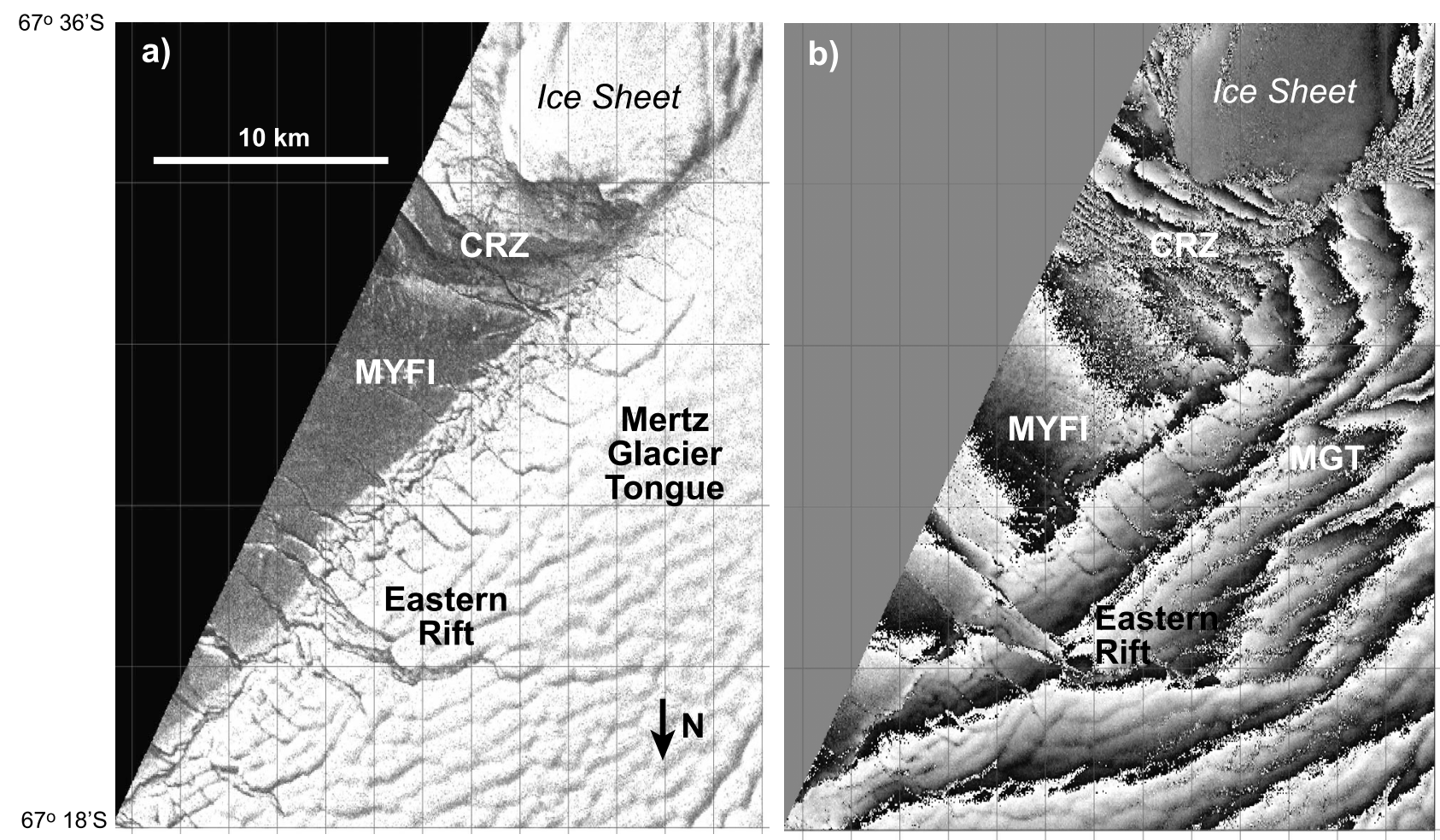

Figure 8. (a) Detail of an ERS-1 and ERS-2 combined SAR amplitude image (May 28 and 29, 1996) of the SE part of the MGT and adjoining MYFI. (b) The corresponding InSAR image. One fringe (from white to black) represents $28 \mathrm{~mm}$ relative surface displacement in 1 day in the line of sight of the satellite to ground. SAR imagery CESA.

mechanical coupling between the MYFI and the MGT. Opening rifts in the MGT constitute localized concentrations of MGT tensile longitudinal strain rates and hence localized stresses applied to the margin of the MYFI, presumably initiating the fast-ice rifting. The rifts are only present in the MYFI and not in the adjacent AFI. Rifts R1-R4 are also apparent in the ICESat elevation profiles (see Figures $6 \mathrm{~b}$ and $6 \mathrm{c})$; the surface elevation inside them is $\sim 3 \mathrm{~m}(\sim 2-4 \mathrm{~m}$ below the MYFI surface (R1 and R2) and $10 \mathrm{~m}$ below the "ramp up" surface (R3), suggesting that they are filled with ice mélange) (similar to Fricker et al. [2005]).

[39] We believe that the rifts played a significant role in facilitating the post-2002 decrease in MYFI extent in response to changing large iceberg distributions. The rapidity and nature of the MYFI breakup (Figure 4) appear to be closely related to the location and orientation of the series of major rifts propagating through the MYFI from the MGT. Once icebergs C-08 and C-09 moved, preferential breakup of the MYFI occurred along the rifts, which formed preexisting lines of weakness. This further demonstrates that a strong, complex, and subtle coupling exists between the MGT and the attached MYFI.

\section{Summary and Conclusions}

[40] We have used various satellite data sets to study the extent, age, and thickness of a large yet diminishing expanse of MYFI connected to the eastern side of the MGT. We have also used the data to examine how the MYFI interacts with the MGT. Our major findings are as follows:

[41] 1. The MYFI slab has components that are at least 25 years old.

[42] 2. This highly consolidated MYFI slab has estimated thicknesses ranging from 10 to $55 \mathrm{~m}$ (an order of magnitude greater than the mean thickness of pack ice in the region).

[43] 3. The area of the MYFI slab was relatively constant at $\sim 2100 \mathrm{~km}^{2}$ between 1997 and late 2001; this area decreased by more than $50 \%$ to $\sim 950 \mathrm{~km}^{2}$ by 2007 , following the departure of icebergs C-09 (in late 2000) and C-08 (in 2002).

[44] 4. The MYFI is attached to the MGT and as a result moves and deforms with it.

[45] 5. Through-cutting rifts, originating in the MGT, propagate for long distances into the MYFI slab and maintain their structure, yet evolve; these rifts contributed to the rapid progressive breakup of the MYFI following the departure of icebergs C-08 and C-09 in 2000-2002.

[46] These findings allow us to draw some important conclusions about the MYFI and its influence on the MGT as outlined below.

\subsection{Growth of MYFI}

[47] The apparent thickness of the MYFI is too great to be explained by simple thermodynamics of freezing of seawater alone (although snow accumulation is a current unknown that may significantly affect the surface elevation as measured by spaceborne laser altimetry). This implies that there must be another process or processes that contribute(s) to its growth. 
We propose that, once it has formed initially as AFI, the MYFI continues to be nourished by accretion of marine ice to its base (although high snow accumulation may also contribute). Marine ice is known to exist in bands of substantial thickness under many Antarctic ice shelves [e.g., Fricker et al., 2001; Holland et al., 2009]. Work is underway to examine the occurrence and role of this process under the Mertz MYFI (B. Galton-Fenzi, personal communication, December 2009). Clearly, in situ measurements are also required to determine the snow accumulation and factors relating to firnification, as these are key unknowns in our current estimates of MYFI thickness from the altimetry data.

[48] While it is known that AFI is highly susceptible to changing atmospheric and oceanic conditions [Heil, 2006; Massom et al., 2009], the situation regarding thick MYFI is less clear. If the Mertz MYFI does rely on marine ice accretion, then it may be particularly sensitive to a warming ocean. Craven et al. [2009] pointed out that the porous lower layers of marine ice are vulnerable to a warming ocean, and modeling studies on the Brunt/Stancomb-Wills Ice Shelf have shown that ice shelf to be vulnerable to destabilization owing to the interaction of its marine ice component with ocean water [Khazendar et al., 2009]. While these vulnerabilities to the integrity of marine ice accretions are straightforward, Eicken and Lange [1989] point out that transport of loose frazil platelets constitutes an advection of latent heat and suggest that beneath a normal thermodynamically growing sea-ice cover, this could act as a buffer against oceanic heat fluxes. With regard to our MYFI region, a warming ocean and higher basal melting near the grounding line of the Mertz Glacier could enhance the production of ISW and even increase the production of suspended frazil ice. This may provide similar protection to the MYFI and even lead to an increased deposition of marine ice, although of course we have yet to identify actual regions of active basal accumulation. It remains an open question whether increased mixing and warmer inflowing waters under the MGT would lead to warmer meltwaters and reduced frazil production instead, and the actual pattern of future local circulation in the absence of adjacent icebergs is also presently a matter of conjecture.

\subsection{Mechanical Coupling}

[49] Findings (1), (2), and (4) in section 4 suggest that the MYFI is thick enough to possess some structural strength and that, on the macro scale, a mechanical coupling may exist between it and the floating MGT to which it is attached. Following Khazendar et al. [2009], who argued that very thick consolidated ice mélange (comprising sea ice, ice shelf debris, firn, and marine ice) plays an important role in holding disparate parts of the Brunt/Stancomb-Wills Ice Shelf system together [see also Hulbe et al., 2005], we propose that the MYFI may enhance the stability of the MGT in a similar fashion to possibly delay its imminent calving via the two conjoined through-cutting rifts. This requires further investigation. Furthermore, Wuite [2006] observed that the MYFI inhibits calving from the eastern compared to the western (polynya) side of the MGT by effectively gluing together the glacier tongue flank.

\subsection{Effect of Icebergs}

[50] Findings (3) and (5) in section 4 suggest that the area extent of the MYFI slab, and thus the area of interaction with the MGT, is affected by the presence or absence of large, grounded tabular icebergs originating from the Ninnis Glacier tongue $\sim 150 \mathrm{~km}$ to the SE. This further suggests that a factor in MYFI (and consequently MGT) stability could be the frequency of future calving and grounding of icebergs from the Ninnis Glacier. How these processes will change in response to a warming climate is unknown. An overriding factor affecting future MYFI extent is also the imminent calving of much of the MGT, i.e., from the two major transverse rifts outward.

[51] Regarding the AFI, both vast and small icebergs act as pinning points for AFI formation and are also "locked in" by the fast ice once it forms, i.e., AFI formation slows the rate of iceberg drift [Massom, 2003]. This increases the residence time of the icebergs, and given that icebergs are a key determinant of fast ice extent and duration, prolongs their role in determining fast ice extent. This is another example of complex feedback between continental ice and sea ice in the Antarctic coastal zone.

[52] In summary, our study has highlighted strong mechanical coupling between a floating glacier tongue and very thick perennial sea ice attached to it. We propose that MYFI may be an important factor in ice tongue/ice shelf stability, one that is missing from current prognostic ice sheet models that aim to determine the dynamic response of ice sheet margins to climate change. We recommend modeling to examine the influence of thick MYFI on the dynamics of ice shelves and floating glacier tongues, along the lines of the recent work on heterogeneous ice shelves by Humbert et al. [2009] and Khazendar et al. [2009]. The processes that control the growth, persistence, and loss of MYFI also require investigation, through coupled ice shelf-ocean modeling. Ice sheet modeling that attempts to predict the evolution of the Antarctic (and possibly Greenland) Ice Sheet and its resulting contribution to sea-level rise should explore whether the role of MYFI and its sensitivity and vulnerability to changing atmospheric and oceanic conditions has any important (and currently neglected) consequences for the evolution of the grounded continental ice. Understanding the influence of thick MYFI on floating ice shelves may be significant to understanding the processes that control the evolution of glacier tongues (and ice shelves) and how these respond to climate change. Underpinning this is a need to address current considerable uncertainty in the thickness of the MYFI slab, and in situ measurements are required to validate the satellite estimates and provide more accurate input into equation (1). This includes improved information on sea ice density, the thickness (relative contribution) and density of marine ice (if it occurs), and snow accumulation and firnification rates.

\subsection{Postscript}

[53] Since this paper was written, a major change occurred in February 2010 in the form of the calving of the outer $78 \mathrm{~km}$ of the MGT [Young et al., 2010]. This followed a collision with iceberg B-9B, which started moving from its location to the east of the MGT in late 2009. This event does not contradict our findings in that MYFI remains to the southeast of the new glacier-tongue terminus.

[54] Acknowledgments. For R.M., A.B.G., N.Y., G.H., and R.W., this work was supported by the Australian Government's Cooperative Research Centres Programme through the Antarctic Climate and Ecosystems 
Cooperative Research Centre (ACE CRC), and contributes to AAS Projects 3024 and 2698 and European Space Agency sponsored IPY projects 4123 and 4129. The International Space Science Institute (Bern, Switzerland) is acknowledged for supporting this study via Projects 137 and 169. H.A.F. was supported by NASA grants NNX06AD40G and NNX06AH39G. B.L.'s visit to the ACE CRC was supported by CNRS; his contribution is within the CRACICE project supported by CNRS, INSU, CNES, and IPEV. We are very grateful to Jason Roberts (ACE CRC and AAD), Ben Galton-Fenzi, and Bill Budd (ACE CRC) for their suggestions and comments on the manuscript, and Pat Langhorne (University of Otago, New Zealand) and one anonymous reviewer for their valuable comments. Radarsat SAR imagery was obtained from the NASA Alaska Satellite Facility (ASF), and Envisat and ERS imagery from ESA. MODIS imagery was obtained from the U.S. National Snow and Ice Data Center (http:// nsidc.org/data/iceshelves_images/), and MODIS Level 1B data were obtained from the MODIS LAADS (Level 1 Atmosphere Archive and Distribution System) archives at the NASA Goddard Space Flight Center (currently accessible at http://ladsweb.nascom.nasa.gov/data/search.html) Landsat imagery was obtained from the NASA Land Processes DAAC (https://lpdaac.usgs.gov/).

\section{References}

Abshire, J. B., X. Sun, H. Riris, J. M. Sirota, J. F. McGarry, S. Palm, D. Yi, and P. Liiva (2005), Geoscience Laser Altimeter System (GLAS) on the ICESat Mission: In-orbit measurement performance, Geophys. Res. Lett. 32, L21S02, doi:10.1029/2005GL024028.

Alley, R. B., and R. A. Bindschadler (Eds.) (2001), The West Antarctic Ice Sheet: Behavior and Environment, Antarct. Res. Ser., vol. 77, AGU, Washington, D. C.

Alley, R. B., and I. M. Whillans (1991), Changes in the West Antarctic Ice Sheet, Science, 254, 959-963.

Berthier, E., B. Raup, and T. Scambos (2003), New velocity map and mass-balance estimate of Mertz Glacier, East Antarctica, derived from Landsat sequential imagery, J. Glaciol., 49(167), 503-511.

Brunt, K. M., O. Sergienko, and D. R. MacAyeal (2006), Observations of unusual fast-ice conditions in the southwest Ross Sea, Antarctica: Preliminary analysis of iceberg and storminess effects, Ann. Glaciol., 44, $183-187$.

Comiso, J. C., D. J. Cavalieri, and T. Markus (2003), Sea ice concentration, ice temperature, and snow depth, using AMSR-E data, IEEE Trans. Geosci. Remote Sens., 41(2), 243-252.

Craven, M., I. Allison, H. A. Fricker, and R. C. Warner (2009), Properties of a marine ice layer under the Amery Ice Shelf, J. Glaciol., 55(192), $717-728$.

Crocker, G. B., and P. Wadhams (1989), Breakup of Antarctic fast ice, Cold Reg. Sci. Technol., 17(1), 61-76.

De Angelis, H., and P. Skvarca (2003), Glacier surge after ice shelf collapse, Science, 299(5612), 1560-1562.

Eicken, H., and M. A. Lange (1989), Development and properties of sea ice in the coastal regime of the southeastern Weddell Sea, J. Geophys. Res., 94(C6), 8193-8206, doi:10.1029/JC094iC06p08193.

Frezzotti, M., A. Cimbelli, and J. G. Ferrigno (1998), Ice-front change and iceberg behaviour along Oates and George V coasts, Antarctica, 1912-96, Ann. Glaciol., 27, 643-650.

Fricker, H. A., and L. Padman (2006), Ice shelf grounding zone structure from ICESat laser altimetry, Geophys. Res. Lett., 33, L15502, doi:10.1029/2006GL026907.

Fricker, H. A., J. N. Bassis, and B. Minster (2005), ICESat's new perspective on ice shelf rifts: The vertical dimension, Geophys. Res. Lett., 32, L23S08, doi:10.1029/2005GL025070.

Fricker, H. A., S. Popov, I. Allison, and N. Young (2001), Distribution of marine ice beneath the Amery Ice Shelf, Geophys. Res. Lett., 28(11), 2241-2244, doi:10.1029/2000GL012461.

Giles, A. B., R. A. Massom, and V.I. Lytle (2008), Fast ice distribution in East Antarctica during 1997 and 1999 determined using Radarsat data, J. Geophys. Res., 113, C02S14, doi:10.1029/2007JC004139.

Giles, A. B., R. A. Massom, and R. C. Warner (2009), A method for subpixel scale feature-tracking using Radarsat images applied to the Mertz Glacier Tongue, East Antarctic, Remote Sens. Environ., 113, 1691-1699.

Grosfeld, K., M. Schröder, E. Fahrbach, R. Gerdes, and A. Mackensen (2001), How iceberg calving and grounding change the circulation and hydrography in the Filchner Ice Shelf-ocean system, J. Geophys. Res. 106, 9039-9055, doi:10.1029/2000JC000601.

Heil, P. (2006), Atmospheric conditions and fast ice at Davis, East Antarctica: A case study, J. Geophys. Res., 111, C05009, doi:10.1029/2005JC002904.

Holland, P. R., H. F. J. Corr, D. G. Vaughan, A. Jenkins, and P. Skvarca (2009), Marine ice in Larsen Ice Shelf, Geophys. Res. Lett., 36, L11604, doi:10.1029/2009GL038162.
Hughes, T. J. (1977), West Antarctic ice streams, Rev. Geophys., 15(1), 1-46, doi:10.1029/RG015i001p00001.

Hulbe, C. L., R. Johnston, I. Joughin, and T. Scambos (2005), Marine ice modification of fringing ice shelf flow, Arct. Antarct. Alp. Res., 37(3), 323-330.

Humbert, A., T. Kleiner, C.-O. Mohrholz, C. Oelke, R. Greve, and M. A. Lange (2009), A comparative modelling study of the Brunt Ice ShelfStancomb-Wills Ice Tongue System. J. Glac., 55(189), 53-65.

Joughin, I., W. Abdalati, and M. Fahnestock (2004), Large fluctuations in speed on Greenland's Jakobshavn Isbrae glacier, Nature, 432(7017), 608-610.

Joughin, I., S. B. Das, M. A. King, B. E. Smith, I. M. Howat, and T. Moon (2008), Seasonal speedup along the western flank of the Greenland Ice Sheet, Science, 320, 781-783.

Khazendar, A., E. Rignot, and E. Larour (2009), Roles of marine ice, rheology, and fracture in the flow and stability of the Brunt/Stancomb-Wills Ice Shelf, J. Geophys. Res., 114, F04007, doi:10.1029/2008JF001124.

Kwok, R., H. J. Zwally, and D. Yi (2004), ICESat observations of Arctic sea ice: A first look, Geophys. Res. Lett., 31, L16401, doi:10.1029/ 2004GL020309

Lambrecht, A., H. Sandhager, D. G. Vaughan, and C. Mayer (2007), New ice thickness maps of Filchner-Ronne Ice Shelf, Antarctica, with specific focus on grounding lines and marine ice, Antarct. Sci., 19(4), 521-532. doi:10.1017/S0954102007000661.

Langhorne, P., V. A. Squire, C. Fox, and T. G. Haskell (2001), Lifetime estimation for a land-fast ice sheet subjected to ocean swell, Ann. Glaciol., $33,333-338$.

Legrésy, B., A. Wendt, I. Tabaco, F. Rémy, and R. Dietrich (2004), Influence of tides and tidal current on the Mertz Glacier, Antarctica, J. Glaciol., 50, $427-435$.

Lewis, E. L. and R. G. Perkin (1986), Ice pumps and their rates, J. Geophys. Res., 91(C10), 11,756-11,762, doi:10.1029/JC091iC10p11756.

Lubin, D., and R. Massom (2006), Polar Remote Sensing. Volume I: Atmosphere and Oceans, $756 \mathrm{pp}$. Springer/Praxis, Berlin

Marsland, S. J., N. L. Bindoff, G. D. Williams, and W. F. Budd (2004), Modeling water mass formation in the Mertz Glacier Polynya and Adélie Depression, East Antarctica, J. Geophys. Res., 109, C11003, doi:10.1029/2004JC002441.

Massom, R. A. (2003), Recent iceberg calving events in the Ninnis Glacier region, East Antarctica, Antarct. Sci., 15(2), 303-313.

Massom, R. A., K. L. Hill, V. I. Lytle, A. P. Worby, M. J. Paget, and I. Allison (2001a), Effects of regional fast-ice and iceberg distributions on the behaviour of the Mertz Glacier polynya, East Antarctica, Ann. Glaciol., 33, 391-398.

Massom, R. A., et al. (2001b), Snow on Antarctic sea ice, Rev. Geophys., 39(3), 413-445, doi:10.1029/2000RG000085.

Massom, R. A., et al. (2006), ARISE (Antarctic Remote Ice Sensing Experiment) in the East 2003: Validation of satellite-derived sea ice data products, Ann. Glaciol., 44, 288-296.

Massom, R. A., K. Hill, C. Barbraud, N. Adams, A. Ancel, L. Emmerson, and M. J. Pook (2009), Fast ice distribution in Adélie Land, East Antarctica: Interannual variability and implications for emperor penguins (Aptenodytes forsteri), Mar. Ecol. Prog. Ser., 374, 243-257.

Oerter, H., J. Kipfstuhl, J. Determann, H. Miller, D. Wagenbach, A. Minikin, and W. Graf (1992), Evidence for basal marine ice in the Filchner-Ronne Ice Shelf, Nature, 358, 399-401.

Payne, A. J., and J. L. Bamber (2004), Conclusions, summary and outlook, in Mass Balance of the Cryosphere, edited by J. L. Bamber and A. J. Payne, pp. 623-639, Cambridge Univ. Press, Cambridge, U. K.

Rémy, J. P., S. Becquevort, T. G. Haskell, and J.-L. Tison (2008), Impact of the B-15 iceberg "stranding event" on the physical and biological properties of sea ice in McMurdo Sound, Ross Sea, Antarctica, Antarct. Sci., 20(6), 593-604.

Rignot, E. (2002), Mass balance of East Antarctic glaciers and ice shelves from satellite data, Ann. Glaciol., 34, 217-227.

Rignot, E., and S. S. Jacobs (2002), Rapid bottom melting widespread near Antarctic Ice Sheet grounding lines, Science, 296, 2020-2023.

Rignot, E., G. Casassa, P. Gogineni, W. Krabill, A. Rivera, and R. Thomas (2004), Accelerated ice discharge from the Antarctic Peninsula following the collapse of Larsen B Ice Shelf, Geophys. Res. Lett., 31(18), L18401, doi:10.1029/2004GL020697.

Rignot, E., J. L. Bamber, M. R. van den Broeke, C. Davis, Y. Li, W. J. van de Berg, and E. van Meijgaard (2008), Recent Antarctic ice mass loss from radar interferometry and regional climate modelling, Nat. Geosci., 1, 106-110, doi:10.1038/ngeo102.

Robin, G. de Q. (1979), Formation, flow and disintegration of ice shelves, J. Glaciol., 24, 259-271.

Scambos, T. A., M. J. Dutkiewicz, J. C. Wilson, and R. A. Bindschadler (1992), Application of image cross-correlation to the measurement of 
glacier velocity using satellite image data, Remote Sens. Environ., 42, $177-186$.

Scambos, T., J. Bohlander, and B. Raup (2001), Updated current year: Images of Antarctic ice shelves, http://www.nsidc.org/data/iceshelves_ images/index.html, Boulder, Colo.

Scambos, T. A., J. A. Bohlander, C. A. Shuman, and P. Skvarca (2004), Glacier acceleration and thinning after ice shelf collapse in the Larsen B embayment, Antarctica, Geophys. Res. Lett., 31(18), L18402, doi:10.1029/2004GL020670.

Scambos, T. A., H. A. Fricker, C.-C. Liu, J. Bohlander, J. Fastook, A. Sargent, R. Massom, and A.-M. Wu (2009), Ice shelf disintegration by plate bending and hydro-fracture: Satellite observations and model results of the 2008 Wilkins Ice Shelf break-ups, Earth Planet Sci. Lett., 280, 51-60.

Scambos, T., R. Ross, R. Bauer, Y. Yermolin, P. Skvarca, D. Long, J. Bohlander, and T. Haran (2008), Calving and ice shelf break-up processes investigated by proxy: Antarctic tabular iceberg evolution during northward drift, J. Glaciol., 54(187), 579-591.

Schutz, B. E., H. J. Zwally, C. A. Shuman, D. Hancock, J. P. DiMarzio (2005), Overview of the ICESat Mission, Geophys. Res. Lett., 32 , L21S01, doi:10.1029/2005GL024009.

Shepherd, A., D. Wingham, and E. Rignot (2004), Warm ocean is eroding West Antarctic Ice Sheet, Geophys. Res. Lett., 31, L23402, doi:10.1029/ 2004GL021106.

Souchez, R., M. Meneghel, J.-L. Tison, R. Lorrain, D. Ronveaux, C. Baroni, A. Lozej, I. Tabacco, and J. Jouzel (1991), Ice composition evidence of marine ice transfer along the bottom of a small Antarctic Ice Shelf, Geophys. Res. Lett., 18(5), 849-852, doi:10.1029/91GL01077.

Spreen, G., S. Kern, D. Stammer, R. Forsberg, and J. Haarpaintner (2006), Satellite-based estimates of sea ice volume flux through Fram Strait, Ann. Glaciol., 44, 321-328.

Thomas, R. H. (2004), Force-perturbation analysis of recent thinning and acceleration of Jakobshavn Isbrae, Greenland, J. Glaciol., 50, 57-66.

Wendler, G., K. Ahlnas, and C. S. Lingle (1996), On Mertz and Ninnis Glaciers, East Antarctica, J. Glaciol., 42(142), 447-453.

Williams, G. D., and N. L. Bindoff (2003), Wintertime oceanography of the Adélie Depression, Deep-Sea Res. II, 50, 1373-1392.

Williams, G. D., N. L. Bindoff, S. J. Marsland, and S. R. Rintoul (2008), Formation and export of dense shelf water from the Adélie Depression,
East Antarctica, J. Geophys. Res., 113, C04039, doi:10.1029/ 2007JC004346.

Williams, M. J. M., R. C. Warner, and W. F. Budd (2002), Sensitivity of the Amery Ice Shelf, Antarctica, to changes in the climate of the Southern Ocean, J. Clim., 15, 2740-2757.

Worby, A., T. Markus, A. Steer, V. Lytle, and R. Massom (2008a), Evaluation of AMSR-E snow depth product over East Antarctic sea ice using in situ measurements and aerial photography, J. Geophys. Res., 113, C05S94, doi:10.1029/2007JC004181.

Worby, A. P., C. A. Geiger, M. J. Paget, M. L. Van Woert, S. F. Ackley, and T. L. DeLiberty (2008b), Thickness distribution of Antarctic sea ice, J. Geophys. Res., 113, C05S92, doi:10.1029/2007JC004254.

World Meteorological Organization (1970), The WMO Sea-Ice Nomenclature: Terminology, Codes and Illustrated Glossary, WMO/OMM/BMO 259, 145 pp., World Meteorological Organization, Geneva, Switzerland.

Wuite, J. (2006), Spatial and Temporal Dynamics of Three East Antarctic Outlet Glaciers and Their Floating Ice Tongues, Ph.D. thesis, Ohio State Univ., Columbus.

Young, N., B. Legrésy, R. Coleman, and R. Massom (2010), Mertz Glacier tongue unhinged by giant iceberg, Aust. Antarct. Mag., 18, 19.

Zwally, H. J., D. Yi, R. Kwok, and Y. Zhao (2008), ICESat measurements of sea ice freeboard and estimates of sea ice thickness in the Weddell Sea, J. Geophys. Res., 113, C02S15, doi:10.1029/2007JC004284.

A. D. Fraser and A. B. Giles, Antarctic Climate and Ecosystems Cooperative Research Centre, Private Bag 80, University of Tasmania, Sandy Bay, Tas 7001, Australia.

H. A. Fricker, Institute of Geophysics and Planetary Physics, Scripps Institution of Oceanography, University of California, San Diego, 9500 Gilman Drive, La Jolla, CA 92093-0225, USA.

G. Hyland, R. A. Massom, R. C. Warner, and N. Young, Australian Antarctic Division, Department of Sustainability, Environment, Water, Population and Communities, Channel Highway, Kingston, Tas 7050, Australia (r.massom@utas.edu.au)

B. Legrésy, LEGOS, CNRS, 14 Av. E. Belin, F-31400 Toulouse, France. 